\title{
Theoretical Analysis
}

\section{A "General Theory of Mental Suffering", and the Role of an Innovative Narrative Therapeutic Approach}

\author{
Derek Botha ${ }^{* a}$
}

[a] Department of Psychology, Rhodes University, South Africa.

\section{Abstract}

This article proposes alternative understandings of certain structuralist informed (Diagnostic and Statistical Manual of Mental Disorders - DSM-IIIrd to 5th Eds.) configurations of mental disorders. Life's negative discourses and the mind's captive responses present a "general theory of mental suffering" which phenomena are classified as modernist, DSM mental disorders, such as addictions, depression, and obsessive-compulsive disorders. Recent research has indicated that the psychedelic drug, psilocybin, has produced safe and effective outcomes for these mental suffering states. In this context, the article draws on the concept of brain plasticity order, firstly, to identify the means for a person to move away from subjection of life's negative, dominant discourses that "capture" the brain, and then to intentionally move towards more acceptable, preferred, ethical subjectivities. These explanations, using the phenomenon of depression, provide the foundation for further proposals that an innovative form of narrative therapy could be a safe, effective and meaningful approach for persons in relationship with other similar ways of mental suffering, such as, anxiety, addiction, obsessive-compulsive disorder, and anorexia nervosa.

Keywords: mental suffering; disorders; DSM; brain plasticity; narrative therapy

\section{Table of Contents}

Objectives

Research questions

Current status

"Capture" - the mystery of mental suffering

Plasticity of the brain

Psychedelics: treatment for depression and a variety of neuropsychiatric disorders

Opportunities for an alternative approach for psychotherapy

Narrative Therapy

Narrative therapy and brain plasticity 
Psychological Thought, 2021, Vol. 14(2), 282-307, https://doi.org/10.37708/psyct.v14i2.572

Received: 2021-01-01. Accepted: 2021-06-19. Published (VoR): 2021-10-31.

Handling Editor: Irina Roncaglia, Chartered Practitioner Sport \& Exercise Psychologist, The National Autistic Society (NAS), United Kingdom.

*Corresponding author at: Rhodes University, South Africa. E-mail: derek.botha@telkomsa.net

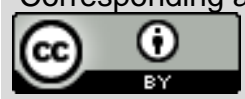

This is an open access article distributed under the terms of the Creative Common Attribution License (https://creativecommons.org/licenses/by/4.0), which permits unrestricted use, distribution, and reproduction in any medium, provided the original work is properly cited.

The mental health field has seen research output from a few researchers, as well as other academics and practitioners, taking cautious but determined steps towards what seems to be an extensive, integrated and united theory of mental suffering (or disorders), but "they would not be so arrogant as to call it that" (Pollan, 2018, p. 383). The focus has tended to be on certain elevated mechanisms in the brain and mind which are hypothesized to underlie and even explicate a number of behavioural disorders and numerous states of mental suffering (e.g., Carhart-Harris et al., 2012, 2014, 2016; Kessler, 2016).

Thomas Insel, a psychiatrist and former head of the American National Institute of Mental Health (NIMH), was asked a question in the following format:

If a certain form of therapy were to be founded on an implied theory of the mental suffering that it claims to alleviate, but is actually able to also remedy a number of forms of mental suffering, what might such outcomes indicate that those mental disorders or sufferings have in common? (Pollan, 2018, p. 383).

And maybe mental disorders in general? His response was: "It doesn't surprise me at all ... The DSM categories we have don't reflect reality. There is much more of a continuum between these disorders than the DSM recognises" (Pollan, 2018, p. 383).

In this context, research is already showing that psychedelic assisted therapy (essentially psilocybin) is providing effective benefits for persons in relationship ${ }^{1}$ with a number of phenomena referred to as mental disorders, such as addiction (Garcia-Romeu et al., 2017), depression and anxiety (Davis et al., 2019; Garcia-Romeu et al, 2019; Griffiths et al., 2016; Ross et al., 2016; Sessa \& Johnson 2015), obsessive-compulsive behaviour (Carhart-Harris et al., 2014), and possibly anorexia nervosa ${ }^{2}$. The fact that this single form of drug therapy

\footnotetext{
${ }^{1}$ An expression such as "a person in relationship with depression" indicates the use of what is referred to in narrative therapy as externalizing conversations. In such contexts, a problem, such as depression, becomes identified as the problem, is externalised from the person, and is not the person or part of the person.

${ }_{2}^{2}$ Researchers at Johns Hopkins University in Baltimore, Maryland (USA), are currently seeking persons in relationship with anorexia nervosa to participate in a research study that "will investigate psychological effects of psilocybin, including whether or not it can help with anorexia". https://hopkinspsychedelic.org/anorexia
} 
has produced positive and effective outcomes for people in relationship with these mental disorders, could mean that they have more similar features, properties and qualities than previously thought. In this framework it would appear that psychedelics affect certain elevated mechanisms in the brain. In addition, it could be that these mechanisms "may underlie, and help explain, a wide variety of mental and behavioural disorders, as well as, perhaps, garden-variety unhappiness" (Pollan, 2018, p. 384). If this hypothesis is reliable, then it raises the next question: could there be a form of psychotherapy that is not based on a psychedelic drug that could also be effective for these identified "mental disorders"?

It is against this background from which the aims and proposals of this article emerge.

\section{Objectives}

Briefly stated, there are two main objectives of this article. The first is to propose a structure for a general and united theory of mental suffering in regard to a few phenomena which are classified as structuralist, modernist mental disorders in editions of Diagnostic and Statistical Manual of Mental Disorders (DSM - III ${ }^{\text {rd }}$ to $5^{\text {th }}$ Eds.) of American Psychiatric Association (APA, 1980-2013). Then, the second flows from, and is integrated with the first, and comprises proposals for an innovative, safe and effective narrative approach to psychotherapy for people who are affected by these phenomena of mental sufferings.

\section{Research questions}

The initial discussion presents the foundational background and motivating factors for the formulation of the proposals in the article. This discussion is presented in the context of two forms of understandings. First there is an examination of current understandings and constructions of phenomena referred to as the various structuralist informed, by the DSM 5 (APA, 1980-2013), configurations of mental disorders. This is followed by an exploration of post-structuralist, person-specific experiences of being captured by the power of the negative discourses encountered in regard to each person's specific "personal, social and ethical problems in living" (Szasz, 2010, p. 292).

In order to address these related questions, this article will use the mental disorder referred to as depressive disorders in the DSM $5^{\text {th }}$ Edition (APA, 1980-2013). This examination, based on depression in relation to brain processes, will be extended to an analysis for determining forms of understandings (Kessler, 2016) of coherences of development and maintenance amongst other "mental disorders". Kessler (2016) used the term "Capture" for the common mechanisms which he saw as underlying the personal experiences of such phenomena ("mental disorders") referred to as addiction, depression, anxiety, mania, obsession and anorexia nervosa (Carhart-Harris et at., 2014; Kessler, 2016, p. 16; Pollan, 
2018, p. 367). It is Kessler's expressed belief that all these mental "disorders involve learned habits of negative thinking and behaviour that hijack our attention and trap us in loops of self-reflection" (Pollan, 2018, p. 383-4).

A brief but important explanation of the related workings of the plasticity of the brain is presented in order to explain the functioning of the neural circuitry in the brain in respect of the brain's interaction with the experiences, challenges and social interactions of life which produce circumstances of which our minds are to make meaning for us.

The article then relates these insights to research indicating safe and effective outcomes using the psychedelic drug, psilocybin, for assisted related therapy for phenomena such as depression, addiction, anxiety, or anorexia. These research results have produced a state where a single drug assisted approach to therapy has been successfully applied to various forms of mental suffering. This then provides opportunities for the proposal for an approach to therapy that is alternative to the use of a psychedelic drug. It is an innovative form of narrative therapy for people in relationship with these various forms of mental suffering in order for these people to embrace meaningful and preferred lifestyles that are free from the subjugating power and capture of their unique and specific mental sufferings.

The analysis of the workings of the plasticity of the brain, that presents the common mechanism for certain phenomena referred to as mental disorders, offers possibilities for providing an alternative psychotherapeutic approach for people in relationship with depression, and, in terms of the hypotheses of this article, for persons in relationship with a number of other universal patterns of behaviour deemed to be DSM-III ${ }^{\text {rd }}$ to $5^{\text {th }}$ Edition mental disorders (APA, 1980-2013). An innovative, post-structuralist informed narrative therapy approach is examined in relation to the understandings that these mental sufferings (disorders) are expressive results of the workings of the plasticity of the brain. In this context, a post-structuralist informed narrative therapy approach is aimed at facilitating conscious "negative" resistances to enable movements away from or out of the negative, anxiety provoking, stressful, challenging, and subjugating discourses that cause the experiences, ways of behaving and lifestyle attitudes deemed to be diagnostic criteria of various forms of "mental disorders". This form of psychotherapy then focuses on facilitating "positive" resistances that are personal, intentional movements towards preferred goals and alternative ways of making meaning in, and of, life for each person.

Thus, this article is intended to present a meta-study encompassing the analyses of correlated theories, practices, and outcomes of research, and the synthesis of these correlations. The aim is to foster innovative, adaptive, integrative and important thinking about the psychology and nature of a group of "mental disorders" that are caused and 
shared by common "personal, social, and ethical problems in living". In addition, for this group of "mental disorders" the aim would also be to advance a related narrative approach to therapy that is proposed as appropriate, meaningful and effective for people sharing such universal experiences of mental sufferings.

\section{Current status}

Current sources and ways of understanding and constructing phenomena referred to as mental disorders are briefly indicated to serve as the comparative bases for the following discussion in regard to a "unified general theory of mental suffering", as well as for a related and appropriate narrative therapeutic approach for persons whose behaviour and attitudes to living create a relationship for them with mental sufferings.

\section{Structuralist informed paradigms - Diagnostic and Statistical Manual of Mental Disorders (DSMs - III ${ }^{\text {rd }}$ to $5^{\text {th }}$ Eds.).}

As briefly as possible, this section presents certain understandings of the phenomenon called depressive disorder, referred to as a mental disorder. It deals with extracts from Western-based diagnostic manuals (DSM - III ${ }^{\text {rd }}$ to $5^{\text {th }}$ Eds.). It is important to note, however, that it has been patently indicated that these manuals do not specify any cause(s) of a mental disorder: "a diagnosis does not carry any necessary implications regarding the causes of the individual's mental disorder or its associated impairments. Inclusion of a disorder in the Classification (as in medicine generally) does not require that there be knowledge about its aetiology" (DSM-IV, p. xxiii). In addition, DSM-III produced the first definition of mental disorder which was included in subsequent editions. However, this definition does not specify that the cause of a mental disorder be stated, or that the disorder be recognised "through the lens of some theoretical system of explanation" (Kutchins \& Kirk, 1997, p. 32). For instance, at present, researchers and clinicians are not able to agree on the aetiology of depression, and the Mayo Clinic (2021) states that "it's not known exactly what causes depression. As with many mental disorders, a variety of factors may be involved", which would be mainly personal factors that would appear to intensify the chance of acquiring or sustaining depressive episodes. Kessler (2016) has stated his view, that "'Depression' is a label used to describe a group of symptoms. It is not a cause" (p. 4).

Allen Frances, the lead editor of DSM-IV, in a frank confession, not only admitted to serious errors in the DSM-IV, but, whilst awaiting the next edition of the DSM (DSM-5), had these outspoken comments: 
There is no definition of a mental disorder. It's (expletive deleted). I mean, you just can't define it ... these concepts are virtually impossible to define precisely with bright lines at the boundaries (Greenberg, 2010).

\section{Multi-constructs of diagnostic criteria of "depressive disorders"}

The DSM-5 diagnostic criteria for depression indicate that this mental disorder varies in severity from gentle, temporary incidents of sadness to critical, unrelenting depression. The most unyielding form of depression is clinical depression, also called major depression or major depressive disorder. In DSM-5, major depressive disorder characterises the exemplary form in this assemblage of disorders. Furthermore, a more chronic form of depression, persistent depressive disorder (dysthymia), was also included as a new diagnosis for circumstances when the mood disturbance continues for at least 2 years in adults or 1 year in children. This diagnosis includes both the DSM-IV diagnostic categories of chronic major depression and dysthymia (APA, 2013, p. 168).

DSM-IV was criticised in regard to claimed dissimilarities between various forms of chronic depression. The reason provided was that for persons with "dysthymia, double depression, or major depressive disorders, ... few differences were observed on a broad range of demographic, clinical, psychosocial, family history, and treatment response variables" (McCullough et al., 2003, p. 614; Klein et al., 2004). For the purposes of this article it is important to note that McCullough et al. (2003) suggested "that chronic depression should be viewed as a single, broad condition that can assume a variety of clinical course configurations" (p. 614). A similar exemplar of criticism of the evidence of minor differences can also be levelled at DSM-5 in regard to the multitude of clinical features that can appear with only slight differences over the continuum of the spread of the multiplicity of forms, characteristics, emotions, appearances, symptoms which the diagnostic criteria attempt to embrace.

\section{Post-structuralist, specific, personal experiences of depression}

Although there are multi-construct possibilities (and problems) provided by the spectrum of diagnostic criteria in more recent DSMs (III ${ }^{\text {rd }}$ to $5^{\text {th }}$ Eds.), especially DSM-5, (APA, p. 155), DSM descriptive systems and criteria of diagnosis, and ways of classification and models or forms of depression, cannot "effectively and satisfactorily encapsulate the heterogeneity of persons" (Taubner et al., 2013), and the nature of their relationships with depression.

However, there has been a useful multiple case study (Robertson et al., 2005), using a qualitative research approach, which studied the stories of lived experiences of a class of self-identified depressed persons. It consisted of interviews in narrative format with each 
member of the group. The study acknowledged the distinctiveness of the depression narrative of each person. Although there were specific and unique experiences in each person's narrative of depression, there were also three broad common themes that emerged from all the narratives. These common themes were:

the participants attached negative meanings to their life experiences; they used negative language, particularly in the form of generalisations, to articulate their stories; and they found socio-political narratives to be subjugating (Robertson et al., 2005, p. 331).

Given this contextual framework of both structuralist informed (DSM 5) and post-structural, subjective experiences of depression, it is necessary to investigate an understanding that would enable the individualisation of personal nuanced directions and relationship patterns of the phenomenon referred to as depression on a hypothesised neurobiological trajectory derived from personal narratives descriptive of life's specific experiences or episodes. This leads to the first objective of the article, which is to examine understandings of neuropsychological circumstances which are premised on the lived experiences from persons in relationship with depression, and interactions of those relationships on the plasticity of the brain. These analyses and interpretations then introduce opportunities for the second objective of the article, which is an examination and discussion of an amended form of a narrative based, therapeutic approach for psychotherapy for any person who may be deemed to be in a relationship with depression, and other mental disorders.

\section{"Capture" - the mystery of mental suffering}

Kessler (2016) has approached his concept of "capture" in the context of determining what transpires when our rational minds have a sense of being commandeered by "something we cannot control" (p. 6). He has indicated that in his research he had hoped "to begin to unravel the mystery of mental suffering, to decipher the underpinnings of a range of intense mental afflictions - including addiction, depression, anxiety, mania, obsessive thoughts, and violent anger", as he saw similarities among them, as well as others such as panic, impulse disorder, hypochondria, as well as some aspects of psychosis (p. 6). In fact, his interest and approach to research the problem and nature of "capture" has been supported by the comments from Steve Bunney, former head of Yale's Department of Psychiatry:

We have the DSM-V, which we use to diagnose and classify hundreds of mental disorders. And yet the biology is suggesting that these disorders are related. It looks very much as if there's this spectrum that's interrelated rather than separate neurotransmitter system diseases ... We 
see one drug working for a variety of problems - or not working. There is also the growing evidence of the huge placebo effect in psychoactive drugs, which is, or ought to be, humbling (in Kessler, 2016, p. 16).

Kessler (2016) presented his understandings in simple terminology of the "capture" by the mind in the context of mental suffering. In this framework, he felt that any impetus, such as a thought, a memory, a place, or a feeling could be a focus for our attention and would then transfer our considerations and feelings. Once our attention developed an increased focus "on this stimulus, the way we think and feel, and often what we do, may not be what we consciously want" (p. 7). This mechanism he named as "capture" which caused "many forms of human behaviour" ( $p .7)$, with its consequences being harmful or favourable. Kessler felt that it was by viewing our behaviour through this lens that he had hoped to provide an explanation of the power that capture had over people when it compelled them to destructive impulses.

Kessler (2016) indicated that his theory of capture consisted of three basic elements: "narrowing of attention, perceived lack of control, and change in affect, or emotional state" (p. 7). Occasionally these elements were also attended by impulses to act. Finally, Kessler stated that when an issue dominated "our attention in a way that feels uncontrollable, and in turn influences our behaviour, we experience capture" (p. 7).

When a person is attracted to a specific stimulus, they perform in response to an emotion or need produced by it. Each response fortifies the neural circuitry. This repetitive way of reacting to the same stimulus time and again sensitizes our "learning, memory and motivational circuitry of our brains" (Kessler, 2016, p. 9), thus creating "emotional and behavioural patterns", as "our thoughts, feeling and actions begin to arise automatically" ( $p$. 9). As Kessler stated: "What started as a pleasure becomes a need; what was once a bad mood becomes continuous self-indictment; what was once an annoyance becomes persecution" ( $p .9)$. He added that whenever a person responded to a stimulus, they reinforced the neural circuitry that induced them to repeat the same destructive thoughts or behaviours. Over time, the draw of this neural sensitization becomes increasingly difficult to resist, and a person's responses become automatic. In such circumstances, when a person's reactions are incongruous with their conscious intents, they will get a sense that they were losing control. Kessler maintained that this "loss of control is a key feature of capture" (p. 41).

For Kessler, then, "capture" represents his understanding of the universal process that underlies mental sufferings such as depression, anxiety, obsession, eating, and addiction. It is his perception that all these mental disorders "involve learned habits of negative thinking 
and behaviour that hijack our attention and trap us in loops of self-reflection" (Pollan, 2018, pp. 383-384).

\section{"Capture" and "anorexia"}

This process of "capture" was recently explored, specifically in a regard to a DSM (III ${ }^{\text {rd }}$ to $5^{\text {th }}$ Eds., APA, 1980-2013) determined mental eating disorder called anorexia nervosa, and that was referred to as "anorexia" from the viewpoint of persons in relationship with that phenomenon (Botha, 2020). "Anorexia" represented an archetype that indicated the universal forms of behavioural patterns and lifestyle attitudes exhibited in response to, and as forms of coping mechanisms against, mental sufferings caused by the antecedent dominant negative discourses in the lives of persons. That article applied innovative analogue and digital thinking processes that indicated that any reliability and validity of the diagnostic criteria in the DSMs (III ${ }^{\text {rd }}$ to $5^{\text {th }}$ Eds., APA, 1980-2013) for the mental eating disorder called anorexia nervosa, did not exist - that is, the diagnostic criteria "did not indicate/point to, nor stand for/represent a mental eating disorder" (Botha, 2020, p. 301). Furthermore, it explained that the eating behavioural patterns and lifestyle "attitudes towards food, body weight and shape" (p. 286), were "essentially coping mechanisms used to provide supports of meaning, identity constructs, conditions of safety and security when people are faced by challenges, demands, conflicts created by specific, unwanted, and negative dominant discourses in their lives" (Botha, 2020, p. 301).

This process then resulted in a statement which reads as follows: the different and personally specific archetypal images exhibited by each person (that is, all deemed to indicate diagnostic criteria for a mental eating disorder called anorexia nervosa) are symbols that stand for, or represent the specific, challenging, lived experiences of each person (e g., leaving home for college; recent death of mother; being a failure at sport and schoolwork; fear of growing up into the "real world") (Botha, 2020, pp. 298-299). This analysis pointed to a wide range of universal patterns of behaviour and attitudes to life, with all of them being deemed to indicate/point to (that is, analogue thinking process) a DSM (III ${ }^{\text {rd }}$ to $5^{\text {th }}$ Eds., APA, 1980-2013) mental eating disorder, but actually stand for/represent (that is, digital thinking process) "personal, social and ethical problems in living" (Szasz, 2010, p. 262) for each person - not a mental eating disorder.

\section{Plasticity of the brain}

The comments, above, from Bunney (see Kessler, 2016, p. 16), Insel (see Pollan, 2018, p. 383), and Kessler (2016), point to a focus on the workings of the neural circuitry in the brain 
as a result of the brain's interaction with our life's experiences, challenges and social interactions which create circumstances that our mind attempts to deal with.

The aptitude to confront and deal with the challenges in life, whether common setbacks or unexpected adversities can be termed "resilience". Graham (2013) captured the essence of resilience by stating that: "The way we can respond with skill to such unwelcome challenges is through resilience. Resilience is the capacity to respond to pressures and tragedies quickly, adaptively, and effectively" ( $p . x x v$ ). Although this ability is partially instinctive in the brain, it is also a mechanism in the brain which can be activated by a conscious process of personal intent and agency. The innate process of brain functioning is termed conditioning, which regulates how a person's learning is encrypted in the neural circuitry of the brain in the first place. The second mechanism of brain functioning is the neuroplasticity. This functioning manages how a person who embraces an attitude of resilience is able to utilise fresh thoughts, feelings and experiences to renew those explicit configurations (Graham, 2013, pp. 323-335). It is the working of neuroplasticity that is one of the main issues of the focus in this article and is linked to the proposal for the use of an innovative form of narrative psychotherapy referred to later.

For instance, under normal circumstances, a person could be confronted by a condition or a discourse in life which the person deems to present as a threatening and stressful situation. The message and feeling are that there is something that is inappropriate, unacceptable, challenging, improper, and so on. A person then becomes anxious, and the anxiety drives the person to attempt to rectify their understanding of the circumstances. When their understanding of the issue has been rectified, an automatic shift in brain activities permit the person not to continue to delve and plunge into depressive thoughts and expectations, but to proceed to the next thought or activity. This shift results in both the feeling and understanding that something is improper and challenging, and the anxiety, to disappear.

However, for a depressive person, this brain shift fails to be activated and then both the feeling and the resultant anxiety increase in strength, and consequently (re)activate the depressive experiences of such a person. Such depressive episodes involve the interactivities of three parts of the brain (Pollan, 2018). First it is the orbital frontal cortex that identifies the feeling and/or understanding that some circumstances have developed that are inappropriate, challenging, seemingly insurmountable, worrisome and fearsome. (The more depressed a person, the more activated will be their orbital frontal cortex). It then sends a signal to the cingulate gyrus indicating the feelings and/or understandings about the challenging circumstances that have developed. In turn, the cingulate generates the frightful stress indicating that something dreadful has happened, could or is developing. The 
cingulate also sends signals to the heart and stomach which signals cause physical sensations related to the feeling of dread or fear (Pollan, 2018).

In the brain, it is the caudate nucleus that allows our thoughts to stream from one to the other and is referred to as the "automatic gearshift". However, in the circumstances as described above, the caudate nucleus becomes "sticky", and the flow of thoughts is interrupted. This state arises as both the orbital frontal cortex and the cingulate gyrus are hyperactive and remain as if locked together in the "on" position. This is referred to as "brain lock" (Schwartz \& Beyette, 1996). As the caudate fails to "shift gear" automatically, the orbital frontal cortex and the cingulate gyrus carry on generating their signals which increase the sense of worrisome and fearsome understandings, and related anxiety. The malfunctioning caudate becomes "stuck" and continues to be swamped with signals from the orbital frontal cortex, resulting in a person experiencing depressive episodes. Reasons for this thought process to become, and remain, "stuck" would vary from person to person.

However, an attitude of deliberately cultivated positive resilience to circumstances being experienced by a person, is able to alter the depression circuit by disengaging the nexus between the orbital frontal cortex and the cingulate gyrus and regularise the functioning of the caudate nucleus. A deliberate, positive resilient approach would enable the growth of new neural brain circuitry that would provide pleasure as opposed to suffering. For instance, prosocial emotions would turbocharge the conditioning of new circuits and new habits, new states of mind and heart, so that they become enduring traits of resilience leading to resilient action (Graham, 2013, p. 278). In turn, this would trigger the release of the neurotransmitter, dopamine, as a "reward" for the new activity and would also assist in consolidating and growing the new neural connections. These new neural circuits would then contest with older ones, and, according to the "use it or lose it" philosophy, the pathological set-ups will wane. The new neural networks will not merely cause the bad habits to be discontinued but will replace the old with new habits (Doidge, 2007, p. 170), and their structures are re-enforced by the process whereby the more frequently neurons fire together, the more powerful their connections become. This is suitably abridged in an axiom known as Hebb's rule which states that neurons that fire together wire together - a theory that is an endeavour to explicate synaptic plasticity, which is the way that brain neurons adjust through the learning process. 


\section{Psychedelics: treatment for depression and a variety of neuropsychiatric disorders}

\section{Psychedelic (psilocybin) assisted treatment, and positive effects}

Research has indicated that both medication (essentially the range of anti-depressant drugs), and forms of behavioural therapy have been only of partial assistance for various forms of depressive sufferings (Kirsch, 2009). However, people in relationship with depression have more recently experienced positive outcomes from treatment with the psychedelic drug, psilocybin (e g., Davis et al., 2020; Garcia-Romeu et al, 2019; Griffiths et al., 2016).

There are two research studies which have relevance for this article. The first (Carhart-Harris et al., 2014) was undertaken with one of the main hypotheses being that, if the rule stands that an "unlocked" brain "is a happy brain, then it would follow that psychedelics could be used to enhance well-being and divergent thinking, even in already healthy individuals" (Carhart-Harris et al., 2014). The second article (Carhart-Harris et al., 2016) published the results of the first examination of the safety and efficacy of psilocybin as a medical therapy for major depression. It was an open-label feasibility trial. The research cohort consisted of 12 persons who had moderate to severe, unipolar, treatment-resistant depression. Two oral doses of psilocybin, being $10 \mathrm{mg}$ and $25 \mathrm{mg}, 7$ days apart, were administered to the participants in a supportive setting, and with no control group. The main outcome gage for feasibility was the intensity of psilocybin's effect as reported by the participants (CarhartHarris et al., 2016, p. 619). It was reported that these two oral administrations of psilocybin were satisfactorily endured, and, after the two administrations, they produced steady reductions in the severity of symptoms (p. 620). In relation to this article, it is important to note that the significant effect produced by the psychedelic drug psilocybin was to assist in the "rewiring" of the brain for persons in relationship with depression.

Qualitative, thematic interviews were conducted with all the patients dealing with treatmentresistance depression 6 months after the psilocybin treatment, "hoping to understand exactly how the psychedelic session had affected them" (Pollan, 2018, p. 377). Two major themes were identified, relating to how the treatment had been beneficial. The first was the participants' description that they rated their depression mainly as "disconnection" (from the self, others, their senses and feelings, core beliefs, spiritual values, or the outside world including nature) (Watts et al., 2017, p. 559). The participants felt "trapped in the prison of 
the mind". Some other expressions were living in a mental prison; like a sack over my head; a mental cage locking me in (Watts et al., 2017, p. 527). All the participants depicted a process which they called "rumination", in terms of which their thoughts would get "stuck" on a single trajectory. Some indicated that, what they referred to as a "gridlock" of involuntary unitary focused negative thoughts, occurred practically relentlessly (Watts et al., 2017, p. 527). Most of the participants indicated that the psilocybin experience had sprung them from their mental prisons to "feeling a sense of mental freedom" (Watts et at., 2017, p. 528).

A follow-up study (Barrett et al., 2020), to the Carhart-Harris et al., (2016) research on the safety and efficacy of psilocybin as a medical therapy for major depression, examined the effects of a single administration of a high dose of psilocybin 1-day before, 1-week after, and 1-month after drug administration. Barrett reported that "a single high dose of psilocybin, administered to properly screened individuals in a carefully controlled setting, can have lasting positive effects on emotional functioning in healthy individuals. These effects were reflected in transient changes in the function of brain regions that support emotional processing" (Dolan, 2020).

In addition to depression, the psychedelic drug, psilocybin, has shown to have provided similar positive therapeutic effects in treating a variety of neuropsychiatric disorders (Barrett et al., 2020, p. 1). They are substance related and addictive disorders (Garcia-Romeu et al., 2019), mood and anxiety related disorders (Davis et al., 2020; Ross et al., 2016), the anxiety of the cancer patient (Griffiths et al., 2016), obsessive compulsive disorder (Moreno et al., 2006), and there is a current project at Johns Hopkins University, Baltimore (USA) planning to study the effects of psilocybin for persons in relationship with anorexia nervosa.

Most of the research in regard to the lasting effects of psilocybin has been published in the past five years and has indicated enduring changes in regard to "personality/attitudes, depression, spirituality, anxiety, wellbeing, substance misuse, meditative practices, and mindfulness" (Adaya et al., 2020, p. 1). Associated with these durable transformations in psychological functioning, there was also a sense of connectedness, emotional innovation, and amplified neural entropy. In addition, "with proper screening, preparation, supervision, and integration, limited aversive side effects were noted" (Adaya et al., 2020, p. 1).

\section{Opportunities for an alternative approach for psychotherapy}

\section{Rationale for implementing an alternative therapeutic approach}

These abovementioned analyses of the disorder called depression, brief reviews of the benefits of the psychedelic drug psilocybin, related interpretations of the plasticity of the brain, and the understandings of commonalities of mental disorders and suffering, all 
combine to provide opportunities for the second objective of this article. This objective is to examine a relevant and alternative psychotherapeutic approach, namely an innovative form of narrative therapy, for any person who may be deemed to be in a relationship with any personal experiences of forms of depression, OCD, addiction, mania, anorexia nervosa, or other possible related mental sufferings that may be called mental disorders.

There are certain reasons for these examinations and proposals as an alternative form of therapy to psilocybin, specifically as opposed to the use of drug treatment. However, they are not meant to detract from any benefits that may be derived from choosing psilocybin for relief from the constrained, negative, destructive and undesirable effects of the plasticity of the brain which result in the various lived experiences of mental suffering. The main reasons for this proposal are that narrative psychotherapy:

- can be used safely for adults, adolescents and the young (for an 8-year-old boy "with" anxiety and anorexia, see Ingamells, 2016a, 2016b).

- is essentially a learning experience, in that resistances, changes and improvements in a person's life are not obtained from external substances or sources, but from the self-agency of, and from within, a person (Kirsch, 2009, p. 162)

- reduces the probability of relapse after a person has shown significant signs of recovery (Bockting et al., 2005), essentially by the nurturing process of a narrative therapist by integrating additional related experiences for a person in order to solidify the positive narratives of a person.

- provides an environment in which people are less likely to drop out of treatment prematurely than they are likely to stop taking drugs (Kirsch, 2009, p. 162).

\section{Innovative form of narrative therapy}

For the reasons described above - that is, in regard to expressing depression as an example of a mental disorder which also reflects the characteristics of other mental disorders and provides positive outcomes when the psychedelic drug psilocybin is used - a related and innovative form of narrative therapy (Botha, 2019), as a meaningful and appropriate psychotherapeutic approach, will now be examined. This will also draw on the workings of the neuroplasticity of the brain in a similar method as it was activated and changed under the influence of psilocybin. In addition, in terms of the discussions above, narrative therapy is proposed as an appropriate and meaningful psychotherapeutic approach for the other related mental sufferings as well. In this context, the earlier comments from Thomas Insel 
must be borne in mind: "It doesn't surprise me at all that the same treatment should show promise for so many indications" (Pollan, 2018, p. 383).

\section{Narrative Therapy}

\section{An innovative and amended approach in narrative therapy to deal with the notion of "capture of mental suffering"}

As explained above, a person is better able to cope with and resist the negative, destructive, worrisome discourses experienced in their lives by consciously rewiring the neuroplasticity of the brain's patterns of responding to life's experiences. In order to achieve the most successful and efficient state of resilience, a person must understand in what way to choose the new thoughts and experiences that would be the most appropriate for the rewiring process. In this context, the leading neuroscientist, Richard Davidson (2012) said that "based upon everything we know about the brain in neuroscience, change is not only possible, but is actually the rule, rather than the exception. It's really just a question of which influences we are going to choose for our brain". Appropriate, meaningful and effective influences can be explored, identified, co-authored, and incorporated in a person's life with the use of narrative therapy.

A narrative psychotherapeutic approach (White, 2007; White \& Epston, 1990) is founded on the notion that a person constructs narratives in order to describe themselves and to provide sense and meaning to their lived experiences and life events. Psychological sufferings tend to be problem-saturated ways of constituting a person's existential account of life and their identities. These are inclined to be inflexible self-narratives that restrict a person's actions, feelings, and thoughts (White, 2007) and obscure the alternatives in life. In such circumstances, White and Epston (1990) have proposed that "when people seek therapy, an acceptable outcome would be the identification or generation of alternative stories that enable them to perform new meanings, bringing with them desired possibilities - new meanings that persons will experience as more helpful, satisfying, and open-ended" (1990, p. 15). In other words, one of the purposes of narrative psychotherapy is to assist people or clients describe the stories of their lives in deeper and more satisfying ways. Outcomes of narrative therapy are usually assessed on the basis of each person's experiences, as it is not a manualised approach for psychotherapy whose outcomes can be assessed in a randomised controlled setting. Epston (2021) provides numerous examples of such personal experiences where a narrative approach has been successful. Another appropriate example is the story of an 8-year-old boy, Wilbur, "with" anxiety and anorexia (Ingamells, 2016a, 2016b). After attending the first few meetings, with his parents, with a narrative therapist, he was seen as Wilbur the Worrier. Narrative therapy then provided him with the ability to resist 
the negative discourses enwrapped in the challenges, pressures and conflicts that caused him to worry incessantly, and through self-agency, to move towards and embrace a more preferred way of living that intentionally made observable his values and moral principles. In other words, as an outcome of narrative therapy, he was able to consciously conduct himself very visibly and overtly as "the patriot of his" own "values" (Veyne, 1993, p. 3). He was then referred to as Wilbur the Warrior. The first article (Ingamells, 2016a) illustrates the practice of nurturing a counter-story to the problem-saturated story presented by Wilbur (Ingamells, 2016a). The second article (Ingamells, 2016b) illustrates and describes the concepts and ways of narrative therapy employed by the therapist.

A recently published article (Botha, 2019) drew on the understandings from White \& Epston (1990), and, focusing on persons in relationship with the phenomenon called anorexia nervosa, adopted an innovative and amended narrative informed therapy approach that was structured on concepts of negative and positive resistances in considering alternative understandings of anorexia nervosa. The article indicated innovative amendments to the traditional narrative therapy approaches, amendments that focused to a greater extent on identifying, naming, exploring, and externalising with the therapist, the nature of the negative, dominant and unwanted discourses and problems that were unfavourably affecting a person's life. It explained narrative therapy as facilitating movements away from (that is, the adopting and application of negative resistances to) the power, influences and subjection by dominant, negative discourses, and then embracing intentional, positive advances (that is, positive resistances) towards more preferred ways of living.

Foucault (1992, p. 27) referred to this process of the use of intentional and positive resilience and resistances as enabling and galvanising a platform for the nurturing of an "ethical subject". In this context, Guilfoyle (2014) has indicated that "Foucault uses the notion of ethics to refer to the relationship a person has with him or herself, as opposed to the constitutive relationship the person has with knowledge or discourse" (p. 170).

\section{Narrative therapy and brain plasticity}

The essential principles, and "maps", of narrative therapy (White, 2007) can be briefly analysed and later explored in relation to the workings of brain plasticity. Narrative therapy consultations initially have a number of undefined possibilities for their directions. All, or only some of the routes may be taken at different stages on the consultations, all however, in keeping with the aims and practices of narrative therapy. The benefit for the client and the therapist is that "there is no 'right' way to go - merely many possible directions to choose from" (Morgan, 2000, p. 2). 
In initial consultations the objective is to facilitate the client's expression of their own knowledge of the problems they are experiencing in their lives, and the meanings and ways that clients have reached them. The basis for this approach is that the client is the expert in all matters of their life, not the therapist. For instance, as indicated above in regard to people in relationship with depression, the common themes that they expressed were that: "the participants attached negative meanings to their life experiences; they used negative language, particularly in the form of generalisations, to articulate their stories; and they found socio-political narratives to be subjugating" (Robertson et al., 2005, p. 331). These meanings, which the participants would have reached in the face of adversity, as usual, consisted of what narrative therapists call "thin descriptions". Thin descriptions do not allow the liberty for any complexities and contradictions of and in life, and, by their very nature, they usually have negative effects on a person's life. The foremost reason is that these descriptions are usually considered to be the absolute truth about a person - for example, they are not worth loving, are addicts, worthless, anorexic, depressive, bi-polar, traumatized, failures at socialising, troublemakers, deserving of punishment, can't stop washing their hands, have the cleanest house in town, and so on. In other words, thin descriptions about a person usually lead to "thin" conclusions about a person's identity, ways of being, and of living life. The thin descriptions frequently construct further "thin" conclusions as a person's skills, knowledges, abilities and competencies become concealed by the power and influence of the "problem-saturated" stories.

However, thin descriptions have also been perceived as not so much as a "problem story", but "no story" at all. Paljakka (2020) has stated: "Or perhaps more specifically, clients and I most often begin our conversations in a place of 'unstories' or 'anti-stories'". She added that, for instance:

The word 'depression' is not a story, and neither are the descriptors of 'lack of motivation' and 'stuckness.' A 'story' has memorable characters, a setting in the person's every-day life, a plotline in which grave and substantial matters are at stake to all involved, and a protagonist who is puzzling over it all in a unique voice and full of feeling and questions. All our lives are full of such stories, - they may be otherwise called 'lived experience' (p. 6)

\section{The "locked brain"}

The fullness of the real and detailed lived experiences which clients explain, provide their specific, personal circumstances leading to their brain becoming locked and the caudate nucleus become "sticky". This activity then stops the flow of thoughts that may be alternative to those contained in the negative lived experiences expressed in the person's narrative and 
leads to these persons' thought process becoming stuck in their negative discourses. Such discourses then offer thin descriptions of a person's lived experiences. It is these negatively experienced thin descriptions which would normally activate a need in a person to seek guidance from a health professional. Such thin descriptions would also tend to inform the processes that would determine a diagnosis as a DSM (III ${ }^{\text {rd }}$ to $5^{\text {th }}$ Eds., APA, 1980-2013) mental disorder.

For a client in therapy, whilst explaining and exploring the stories of their lived experiences, a narrative therapist would then be interested in separating the person's identity from the problems for which they seek therapeutic assistance. It would involve externalising conversations (White \& Epston, 1999; White, 2007, 2011) which would assist a client to break away from the influences and subjugating powers of the negative, problem-saturated stories that build and retain the neural circuitry of the locked brain. Externalising conversations would also involve, not only the naming of the problem (for instance, the anger, the depression, the worry, the temper tyrant, the mistrust, the hopelessness), but also tracing the history of the problem, its socio-cultural environment, other persons related to the problem, how the problem emerges, the relative effects of the problem on the person and their life, and the effects of the person on the life of the problem. This storying process enables a separation of identity between the problem and the person. It is an important concept in the tradition of narrative therapy "as one of the anti-therapies to the medical model, the master colonizer - the vernacular of the unstories of the DSM" (Paljakka, 2020, p. 8).

\section{Deconstructing the problem-saturated stories}

Further understandings of narrative therapy are drawn upon in order to continue with the activity of galvanising personal agency in "moving away from or out of subjugating discourses" (Lee, 2004, p. 226). Such further narrative practices explore ways of deconstructing ("taking apart") the specific ideas, beliefs and practices that are regarded as "taken for granted", "common place understandings" or "truths" (Morgan 2000, p. 45), that support the life of the problem and the problem story and provide assistance for the malfunctioning of the caudate nucleus.

This deconstruction process provides for the emergence of occurrences that would gainsay or be exterior to the dominant problem narratives. In other words, the narrative therapist would be listening for occasions when the negative problem story has had less or no effect or impact on the life of a person. These are known as "unique outcomes" in narrative practice, and, for instance, may comprise one or more of the following features: plans, beliefs, feelings, desires, thoughts, or abilities. The history and meanings of the "unique 
outcomes" need to be explored and named, which would result in the emergence of alternative stories in a person's life, with rich, thick descriptions. This process then assists in unlocking the orbital frontal cortex and the cingulate gyrus and enabling the caudate nucleus to "change gears automatically" and allow for a free flow of varying or alternative thoughts. The explored and named alternative stories with thick descriptions assist in the cultivation of Foucault's "ethical subject" (Foucault, 1992, 1997a).

\section{"Thickening" positive narratives of the "ethical subject"}

The accounts of an ethical subject should be nurtured by the narrative therapist by integrating further related experiences for a client (e.g., Foucault, 1997b, 2001). The intention is to encourage the preservation of thickened accounts of an ethical subject. This imperative is based on the general principle of neural plasticity: that it is a use-it-or-lose-it phenomenon (Pollan, 2016, p. 8) which acts to prevent any repeated form of destructive and negative narratives emerging in a client's life. It will then allow a free flow of thoughts by the caudate nucleus, and thus prevent the orbital frontal cortex and the cingulate gyrus from again locking.

In the practice of nurturing a client's "thickening" of their ethical subjectivity, a narrative therapist should collaborate with a client to determine the way a client should behave and organise their life in congruence with their principles or values that are significant for them. These principles or values should afford each person - the former anorexic, addict, obsessive, depressive - with reference systems that they would experience as distinctive for them, in their specific settings and their life's circumstances (Botha, 2019, p. 191; see also, Guilfoyle, 2014, p. 188).

Furthermore, there is a related practice for the purpose of promoting a thickened account of the ethical subjectivity, which is for a narrative therapist to support a client to become "the patriot of his or her own values" (Veyne, 1993, p. 3). In terms of this practice a client would be assisted to behave in ways that would reveal their intentional commitments to the principles and values aligned with their ways of living (Botha, 2019). There are two such possible empowering practices. In the first, a client could employ training techniques in order to control their own future conduct that would be reflective of their ethical subjectivity (Botha, 2019; Foucault, 2001). These training procedures entail perceptions of conscious and active intentionality that include practices of "meditation, of memorisation of the past, of examination of conscience, of checking representations that appear in the mind, and so on" (Foucault, 2001, p. 11). The second option is for the therapist to incorporate, in therapy, White's narrative practices (e g., White, 2000, 2007), such as re-membering and definitional ceremonies, which are cogent and influential techniques for the development of fortified 
ethical subjects. In terms of the working of the plasticity of the brain, these techniques assist in continuously keeping an "unlocked" brain which will enable the caudate nucleus to uninterruptedly keep alternative, different, even challenging thoughts, flowing through from the orbital frontal cortex to the cingulate gyrus.

\section{Concluding comments}

This article is not meant to be a prescriptive analysis of alternative understandings for causes of onset, and maintenance, of depression and other mental conditions, and the use of an alternative, post-structuralist source of psychotherapy, namely narrative psychotherapy. It presents some related concepts that could be further investigated as "work in progress" in order to establish more committed understandings towards an extensive, integrated and united theory of mental suffering, and the application of an innovative form of narrative therapy as a reliable, effective and valid psychotherapeutic approach for numerous forms of mental suffering.

The basic narrative for this article commences with the comment by Thomas Insel, who stated that “... the DSM categories we have don't reflect reality. There is much more of a continuum between these disorders than the DSM recognises" (Pollan, 2018, p. 383). In order to examine this statement more fully, this article initially draws on aspects of the mental disorder referred to as depressive disorders in the DSM $\mathrm{II}^{\text {rd }}$ to $5^{\text {th }}$ Editions. It then also encompasses a further related analysis in order to determine additional forms of understandings (Kessler, 2016) of consistencies of initiation, development and maintenance amongst other related "mental disorders". It is proposed that higher-order mechanisms of the brain, with brain structures functioning both independently and in definitive and collaborative ways, could then present images of brain processes that could be deemed to be symptomatic of the onset and maintenance of a mental disorder. The results of such process of the workings of the brain have been referred to by Kessler (2016) as being the "Capture" of the underlying personal experiences that lead to lived expressions and behaviours that are deemed to be signs of "mental disorders", referred to as addiction, depression, anxiety, mania, obsession and anorexia nervosa (Carhart-Harris et at., 2014; Kessler, 2016, p. 16; Pollan, 2018). In this regard, Pollan has stated that addiction, "depression, obsession and eating disorders - all are exacerbated by the tyranny of an ego and the fixed narratives it constructs about our relationship to the world" (2018, p. 367). The related workings of the plasticity of the brain incorporated in these proposals then provide the structures that form a general theory of mental suffering for related phenomena which, however, are currently classified as different, specifically identifiable mental disorders in DSMs (III ${ }^{\text {rd }}$ to $5^{\text {th }} \mathrm{Eds}$., APA, 1980-2013). 
It is in these contexts of the plasticity of the brain that outcomes of current research have already generated evidence that psychedelic assisted therapy (psilocybin) is safe and also provides helpful assistance for people in relationship with various mental disorders, such as depression and anxiety, obsessive compulsive behaviour, and, possibly, anorexia nervosa. In other words, the contention in this article is that if a specific form of psychedelic drug therapy (psilocybin) has produced positive and effective outcomes for persons in relationship with these differently DSM (III ${ }^{\text {rd }}$ to $5^{\text {th }}$ Eds., APA, 1980-2013) classified mental disorders, it could indicate that they embody more analogous attributes, properties and qualities than hitherto considered, and deemed related. If these understandings and related hypothesis of an integrated and united theory of mental suffering, are reliable (and valid), then it raises the possible corollary: could there be an alternative form of therapy, that is not based on a psychedelic drug that could also be safe and effective for these common and unified forms of mental suffering?

An appropriate, suitable and innovative, post-structuralist form of psychotherapy, namely, narrative therapy, is described in detail, for people enduring the discussed unified forms of mental conditions. One of its strengths is its relevant capacity to address malfunctioning aspects of the workings of the plasticity of the brain, which facilitate processes creating unified forms of mental conditions referred to in this article. In this context, this poststructuralist informed narrative therapy approach is designed to facilitate conscious "negative" resistances to enable movements away from or out of the "capture" of negative, anxiety provoking, stressful, challenging and subjugating discourses that cause the various personal experiences and lived expressions which are reflective of what this article describes as contributing towards a "general theory of mental suffering". Then, this form of psychotherapy focuses on facilitating "positive" resistances which are personal, intentional movements towards preferred goals and alternative ways of making meaning in, and of, life for each person. Thus, this innovative form of narrative therapy is proposed as safe, effective, appropriate and meaningful for people sharing such universal ways of being, and experiences of a general theory of mental conditions and suffering.

\section{Funding/Financial Support}

The author has no funding to report

\section{Other Support/Acknowledgement}

The author has no support to report.

\section{Competing Interests}

The author has declared that no competing interests exist. 


\section{References}

Adaya, J. S., Mitzkovitz, C. M., Bloesch, E. K., Davoli, C. C. \& Davis, A. K. (2020, June). Long-term effects of psychedelic drugs: A systematic review. Neuroscience and Bio-behavioural Reviews, 113, 179-189. https://doi.org/10.1016/j.neubiorev.2020.03.017

American Psychiatric Association (APA). (1980, 1987, 1994, 2000, 2013). Diagnostic and Statistical Manual of Mental Disorders, (III ${ }^{\text {rd }}$ to $5^{\text {th }}$ Eds.). https://doi.org/10.1176/appi.books.9780890425596.dsm05

Barrett, F. S., Doss, M. K., Sepeda, N. D., Pekar, J. J., \& Griffiths, R. R. (2020). Emotions and brain function are altered up to one month after a single high dose of psilocybin. Scientific Reports, 10, 2214. https://doi.org/10.1038/s41598-020-59282-y

Bockting, C. L. H., Schene, A. H., Spinhoven, P., Koeter, M. W. J., Wouters, L. F., Huyser, J., Kamphuis, J. H. \& Delta Study Group. (2005). Preventing relapse/recurrence in recurrent depression with cognitive therapy: A randomized control trial. Journal of Consulting and Clinical Psychology, 73(4), 647-657. https://doi.org/10.1037/0022-006X.73.4.647

Botha, D. (2019) 'Anorexic adolescents': Negative and positive resistances in narrative therapy. Journal of Constructivist Psychology, 32(2), 181-198.

https://doi.org/10.1080/10720537.2018.1433089

Botha, D. (2020). Analysing anorexia nervosa: digital logic provides alternative meanings of its nature, leading to alternative forms of psychotherapy. Journal of Psychological Thought, 13(2), 286307. https://doi.org/10.37708/psyct.v13i2.471

Carhart-Harris, R. L, Erritzoe, D, Williams, T, Stone, J. M., Reed, L. J., Colasanti, A., Tyacke, R. J., Leech, R., Malizia, A. L., Murphy, K., Hobden, P., Evans, J., Feilding, A., Wise, R. G., \& Nutt, D. J. (2012). Neural correlates of the psychedelic state as determined by fMRI studies with psilocybin. Proceedings of the National Academy of Sciences of the USA, 109(6), 2138-2143. https://doi.org/10.1073/pnas.1119598109

Carhart-Harris, R. L, Leech, R., Hellyer, P. J., Shanahan, M., Feilding, A., Tagliazucchi, E., Chialvo, D. R., \& Nutt, D. J. (2014). The Entropic Brain: A theory of conscious states informed by neuroimaging research with psychedelic drugs. Frontiers in Human Neuroscience, 8(20). https://doi.org/10.3389/fnhum.2014.00020 
Carhart-Harris, R. L., Bolstridge, M., Rucker, J., Day, C. M. J., Erritzoe, D., Kaelen, M., Bloomfield, M., Rickard, J. A., Forbes, B., Feilding, A., Taylor, D., Pilling, S., Curran, V., H., \& Nut, D. J. (2016). Psilocybin with psychological support for treatment-resistant depression: an openlabel feasibility study. Lancet Psychiatry, 3, 619-627. https://doi.org/10.1016/S22150366(16)30065-7

Davidson, R. (2012). Cited in L. Graham (2015). In Bouncing back: Rewiring your brain for maximum resilience and well-being (p. xxviii). New World Library.

Davis, A. K., Barrett, F. S., \& Griffiths, R. R. (2020). Psychological flexibility mediates the relations between acute psychedelic effects and subjective decreases in depression and anxiety. Journal of Contextual Behavioral Science, 15, 39-45.

https://doi.org/10.1016/j.jcbs.2019.11.004

Doidge, N. (2007). The brain that changes itself: Stories of personal triumph from the frontiers of brain science. Penguin Books.

Dolan, E. W. (2020). A single dose of psilocybin alters brain function up to one month later. Psychedelic Drugs.

Epston, D. (2021). Archive of resistance: Anti-anorexia/anti-bulimia.

https://www.narrativeapproaches.com/resources/anorexia-bulimia-archives-of-resistance

Foucault, M. (1992). The use of pleasure: The history of sexuality (Vol. 2). Penguin.

Foucault, M. (1997a). On the genealogy of ethics: An overview of work in progress. In P. Rabinow (Ed.), Michel Foucault: Ethics, subjectivity and truth, (Vol. 1, pp. 253-280). New Press.

Foucault, M. (1997b). The ethics of concern for self as a practice of freedom. In P. Rabinow (Ed.), Michael Foucault: Ethics, subjectivity and truth, (Vol. 1, pp. 281-302). New Press.

Foucault, M. (2001). The hermeneutics of the subject: Lectures at the College de France 1981-1982. Palgrave Macmillan.

Garcia-Romeu, A., Griffiths, R. R., \& Johnson, M. W. (2017). Psychedelic-associated addiction remission: An online survey. Drug and Alcohol Dependence, 171, e69. https://doi.org/10.1016/j.drugalcdep.2016.08.199

Garcia-Romeu, A. Davis, A. K., Erowid, F., Erowid, E., Griffiths, R. R., \& Johnson, M. W. (2019). Cessation and reduction in alcohol consumption and misuse after psychedelic use. Journal of Psychopharmacology, 33(9), 1088-1101. https://doi.org/10.1177/0269881119845793

Graham, L. (2013). Bouncing back: Rewiring your brain for maximum resilience and well-being. New World Library. 
Greenberg, G. (2010). Inside the battle to define mental illness. Wired. http://www.wired.com/2010/12/ff_dsmv/

Griffiths, R. R, Johnson, M. W., Carducci, M. A., Griffiths, R. R., Johnson, M. W., Carducci, M. A., Umbricht, A., Richards, W. A., Richards, B. D., Cosimano, M. P., \& Klinedinst, M. A. (2016). Psilocybin produces substantial and sustained decreases in depression and anxiety in patients with life-threatening cancer: A randomized double-blind trial. Journal of Psychopharmacology, 30(12), 1181-1197. https://doi.org/10.1177/0269881116675513

Guilfoyle, M. (2014). The person in narrative therapy: A post-structural, Foucauldian account. Palgrave McMillan.

Ingamells, K. M. (2016a). Wilbur the worrier becomes Wilbur the warrior. A teaching story for narrative family therapists. Journal of Systemic Therapies, 35(4), 43-57. https://doi.org/10.1521/jsyt.2016.35.4.43

Ingamells, K. M. (2016b). Learning How to Counter-Story in Narrative Therapy (With David Epston and Wilbur the Warrior). Journal of Systemic Therapies, 35(4), 58-71. https://doi.org/10.1521/jsyt.2016.35.4.58

Kessler, D. A. (2016). Capture: Unravelling the mystery of mental suffering. Harper Wave.

Kirsch, I. (2009). The Emperor's New Drugs: Exploring the antidepressant myth. Random House.

Klein, D. N., Santiago, N. J., Vivian, D., Blalock, J. A., Kocsis, J. H., Markowitz, McCullough J. P., Rush, A. J., Trivedi, M. H., Arnow, B. A., Dunner, D. L., Manber, R., Rothbaum, B., Thase, M. E., Keitner, G. I., Miller, I. W., Keller, M. B. (2004). Cognitive-Behavioural Analysis System of Psychotherapy as a Maintenance Treatment for Chronic Depression. Journal of Consulting and Clinical Psychology, 72(4), 681-688. https://doi.org/10.1037/0022-006X.72.4.681

Kutchins, H. \& Kirk, S. A. (1997). Making Us Crazy: DSM: The Psychiatric Bible and the Creation of Mental Disorders. Simon \& Schuster.

Lee, C. (2004). Agency and purpose in narrative therapy: Questioning the post-modern rejection of metanarrative. Journal of Psychology and Theology, 32, 221-231. https://doi.org/10.1177/009164710403200307

Mayo Clinic (2021). Depression: Major depressive disorder. https://www.mayoclinic.org/diseasesconditions/depression/symptoms-causes/syc-20356007 
McCullough, J. P., Jr., Klein, D. N., Borian, F. E., Howland, R. H., Riso, L. P., Keller, M. B., \& Banks, P. L. C. (2003). Group Comparisons of DSM-IV Subtypes of Chronic Depression: Validity of the Distinctions, Part 2. Journal of Abnormal Psychology, 112(4), 614-622. https://psycnet.apa.org/doi/10.1037/0021-843X.112.4.614

Moreno, F., Wieland, C., Taitono, E. \& Delgado, P. (2006). Safety, tolerability, and efficacy of psilocybin in 9 patients with obsessive compulsive disorder. Journal of Clinical Psychiatry, 67(11), 1735-1741.

Morgan, A. (2000). What is narrative therapy? An easy-to-read introduction. Dulwich Centre Publications.

Paljakka, S. (2020). What's So Narrative About Narrative Therapy? Journal of Contemporary Narrative Therapy, 3, 4-24. http://www.journalcnt.com/

Pollan, M. (2018). How to change your mind: The new science of psychedelics. Penguin.

Robertson, A., Venter, C., \& Botha, K. (2005). Narratives of depression. South African Journal of Psychology. https://doi.org/10.1177/008124630503500210

Ross, S., Bossis, A., Guss, J., Agin-Liebes, G., Malone, T., Cohen, B., Mennenga, S. E., Belser, A., Kalliontzi, K., James, J., Sum, Z, Corby, P., \& Schmidt, B. L. (2016). Rapid and sustained symptom reduction following psilocybin treatment for anxiety and depression in patients with life-threatening cancer: a randomized controlled trial. Journal of Psychopharmacology, 30, 1165-1180. https://doi.org/10.1177/008124630503500210

Schwartz, J. M. \& Beyette, B. (1996). Brain lock: Free yourself from obsessive-compulsive behaviour. Regan Books/Harper Collins.

Sessa, B., \& Johnson, M. W. (2015). From addiction to recovery using altered states of consciousness. In: R. Dickins, (Ed.). Psychedelic Press UK, 1. Psychedelic Press, pp. 71-80.

Szasz, T. S. (2010). The myth of mental illness. New York. (Original work published 1974).

Taubner, S, Wiswede, D. \& Kessler, H. (2013). Neural activity in relation to empirically derived personality syndromes in depression using a psychodynamic fMRI paradigm. Frontiers in Human Neuroscience. https://doi.org/10.3389/fnhum.2013.00812

Veyne, P. (1993). The final Foucault and his ethics. Critical Inquiry, 20, 1-9. http://hdl.handle.net/20.500.12424/655511 
Watts, R., Day, C., Krzanowski, J., Nutt, D., \& Carhart-Harris, R. (2017). Patients' accounts of increased 'connectedness' and 'acceptance' after psilocybin for treatment-resistance depression. Journal of Humanistic Psychology, 57(5), 520-564. https://doi.org/10.1177/0022167817709585

White, M. (2000). Reflections on narrative practice: Essays and interviews. Dulwich Centre.

White, M. (2007). Maps of narrative practice. Norton \& Company Ltd.

White, M. (2011). Narrative Practice: Continuing the Conversations. Norton \& Company Ltd.

White, M., \& Epston, D. (1990). Narrative means to therapeutic ends. Norton \& Company Ltd.

\section{About the Author}

Derek Botha was a lawyer, and professor of finance (University of Cape Town), then trained as a psychotherapist in South Africa and Australia, and is currently a practising narrative therapist. He is also an Honorary Research Associate in the Department of Psychology, Rhodes University, Grahamstown, South Africa. He now publishes in the field of mental health, and his research interests revolve around aspects of anorexia nervosa.

\section{Corresponding Author's Contact Address ${ }^{[T O P]}$}

E-mail: derek.botha@telkomsa.net 